\title{
A intervenção terapêutica breve e a pré-cirurgia infantil
}

\author{
Maria de Fátima Xavier da Silva
}

Trinca, A. M. T. (2003). A intervenção terapêutica breve e a pré-cirurgia infantil. São Paulo: Vetor.

A psicoterapia breve de crianças é uma prática pouco estudada e pesquisada, apesar de sua grande utilização na clínica, principalmente em instituições, ambulatórios e hospitais, uma vez que, na maioria das vezes, esse tipo de atendimento psicológico ocorre mais por conhecimento empírico, aliado à boa vontade e à dedicação dos psicólogos, do que por uso de teorias e técnicas fundamentadas em pesquisas. Diante dessa constatação, a autora objetivou em sua pesquisa desenvolver e validar um modelo de intervenção psicológica breve para crianças na situação pré-cirúrgica, com a utilização do Procedimento de Desenhos-Estórias (D-E).

Esse livro resultou da tese de doutorado da autora, que se interessou por procedimentos médicos e hospitalares, tendo como foco de suas preocupações as fantasias e angústias das crianças que aguardavam intervenções cirúrgicas. Constituído de quatro capítulos e 361 páginas, foi prefaciado por Ryad Simon, professor titular do Instituto de Psicologia da Universidade de São Paulo.

No capítulo inicial, Ana Maria Trapé Trinca traz a trajetória da sua pesquisa, desde as dificuldades para conseguir uma instituição hospitalar que oferecesse condições mínimas para a realização do estudo até a precariedade do atendimento num hospital público, acrescentando ainda os resultados da sua pesquisa anterior, que se transformou em dissertação de Mestrado. Destaca os estudos encontrados sobre psicoterapia breve de criança e constata a pouca produção científica de teorias e práticas, principalmente no Brasil. $\mathrm{Na}$ seqüência, indica as mais recentes contribuições para a psicoterapia breve de crianças no contexto de pré-cirurgia, com base nos referenciais psicanalíticos. Nesse capítulo introdutório, a autora apresenta as características do instrumento psicológico utilizado, o Procedimento de Desenhos-Estórias (D-E), uma técnica de investigação da personalidade, de Walter Trinca, nesse contexto empregada como um procedimento psicoterápico com o objetivo de intermediar a comunicação do profissional e paciente.

No segundo capítulo, Materiais e métodos, a autora discute o método qualitativo, justificando seu uso em razão do propósito da sua pesquisa, que é observar os fenômenos de maneira a evidenciar quando, onde e como eles aparecem, independentemente da sua transformação em dados mensuráveis. Em seguida, descreve os sujeitos em relação ao número, gênero, idade, nível socioeconômico e escolaridade; cita o local em que foi realizada a pesquisa, descreve o procedimento usado na

\footnotetext{
${ }^{1}$ Endereço para correspondência:
}

E-mail: fatxavier@ig.com.br seleção dos participantes, explica o objetivo das entrevistas e como foram realizadas com a mãe e a criança. Enfatiza que a aplicação do Procedimento de Desenhos-Estórias como instrumento de intermediação terapêutica ocorreu obedecendo às instruções de uso do mesmo, sendo acrescido de intervenções terapêuticas baseadas nas observações clínicas que ocorriam no decorrer de todo o trabalho de atendimento. Procurou, de uma forma didática, informar cada passo percorrido para de alcançar o objetivo da sua pesquisa. Deixa clara a finalidade de se fazer uma, duas ou três sessões de aplicação do instrumento, explicando que o número de sessões depende da evolução do caso e que o instrumento deve ser aplicado obedecendo a um intervalo de tempo de uma sessão para outra, o que facilita o processo de elaboração dos conteúdos manifestos na aplicação anterior. Finaliza o capítulo afirmando que a avaliação e análise dos dados foram fundamentados no referencial teórico psicanalítico, de acordo com Freud, Melanie Klein, Winnicott e Bion.

No terceiro capítulo, Resultados, a autora apresenta os casos clínicos explicitando alguns itens como: identificação da criança, informações sobre a cirurgia, resumo das entrevistas e suas impressões no contato com a criança. Em seguida apresenta o material clínico, composto dos casos atendidos, bem como as interpretações que resultaram das correlações dos procedimentos, que inclui os protocolos do teste compostos pelas histórias e respectivos desenhos, entrevistas e observações clínicas. No encerramento de cada caso, a pesquisadora traça um paralelo da evolução do mesmo entre a primeira e as demais sessões e a partir desse resultado busca evidência de validade clínica da técnica utilizada, associando o Procedimento de Desenhos-Estórias com os demais instrumentos. A confirmação de validade clínica está fundamentada na constatação de conteúdos de mudanças significativas na maioria dos casos atendidos, o que leva a acreditar que o D-E é válido como instrumento terapêutico.

A obra é finalizada com o capítulo sobre as Implicações, discussões e conclusões, no qual a autora indica sugestões para a formulação de um modelo de atendimento psicológico breve. Explica que esse modelo é voltado a crianças durante o período pré-cirúrgico, compreendendo a realização de, no máximo, três sessões, e pode ser mais adequado em situações emergenciais em que a psicoterapia prolongada torna-se inviável. Em seguida, descreve o modelo de atendimento 
proposto e destaca sua finalidade e importância dentro do processo de intervenção psicológica breve para crianças. Discute as outras técnicas terapêuticas usadas na situação pré-cirúrgica e constata que todas têm como objetivo ajudar o indivíduo num momento importante de crise a superar suas dificuldades. No entanto, o modelo de atendimento indicado para essa população, além de utilizar material básico e não impor dispêndios financeiros ao profissional e nem à instituição, tem a vantagem de ser uma intervenção rápida, eficaz e possibilitar a investigação de características mais profundas da personalidade da criança. Esse modelo de psicoterapia breve, de acordo com a autora, não exclui outras possibilidades de avaliações e interpretações pautadas tanto no referencial psicanalítico como em outras abordagens teóricas e práticas psicológicas.

Conclui o último capítulo considerando que, embora a elaboração do processo em cada caso tenha variado, os resultados demonstraram que, no conjunto, o Procedimento de Desenhos-Estórias pôde auxiliar a criança a elaborar parte de seus conflitos nessa situação de crise pré-cirúrgica. Portanto, foi considerado válido como instrumento intermediário de comunicação terapêutica, o qual possibilita o contato com emoções que de outro modo poderiam permanecer inacessíveis.
Essa obra traz uma contribuição importante para uma área pouco explorada e carente de pesquisas que buscam desenvolver procedimentos psicoterápicos breves para crianças, verificando a validade deles. Oferece um modelo de atendimento psicológico breve para criança fundamentado nos resultados significativos de uma pesquisa e, ainda que o objetivo da mesma tenha sido buscar evidência de validade clínica, ou seja, idiográfica, relativa ao sujeito, a autora não deixou de fazer uma avaliação global, nomotética, relativa ao grupo. Cabe ressaltar que, mesmo não tendo o propósito de desenvolver o estudo numa perspectiva mais psicométrica, a autora apresenta material que seria compatível com um tratamento estatístico mais sofisticado que conferisse uma maior confiabilidade dos resultados relativos ao grupo.

A proposta de utilizar um instrumento projetivo voltado à avaliação psicológica como uma técnica que possibilita a expressão das emoções de forma mais rápida e eficaz é relevante e também inovadora no nosso meio. Esse método pode ser mais um recurso disponível aos psicólogos hospitalares, de ambulatórios ou mesmo o clínico em situações emergenciais; portanto, pode ser indicado aos estudantes de psicologia e profissionais que atuam na área clínica e da saúde que, por razões diversas necessitem utilizar a psicoterapia breve.

Sobre a autora:

Maria de Fátima Xavier da Silva é psicóloga e mestranda em Psicologia na Universidade São Francisco. 